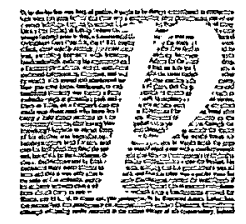

\title{
Imagen visual y semejanza: Williams y Heaney en torno a Brueghel ${ }^{1}$ \\ Irene Artigas Albarelli \\ Facultad de Filosofia y Letras \\ Universidad Nacional Autónoma de México
}

Un na ekphrasis es la representación verbal de una representación visual. El concepto, aunque parece sencillo, entraña problemas que se relacionan con la idea misma de representar, de volver a presentar, de hacer presente algo que es otra cosa. Si tenemos una representación verbal sobre otra representación, ahora visual, es de esperar que la primera siempre ponga en juego ciertos conceptos referentes al lenguaje, que compare su medio con el de lo que representa, que se cuestione la forma y la posibilidad de hacerlo. La idea de este trabajo es analizar la manera en la cual el problema de la representación aparece en los poemas "Haymaking" y "The Corn Harvest" de William Carlos Williams (1962) y "The Seed Cutters" de Seamus Heaney (1975). Comencemos por dejar claro que en realidad se trata de ekphrasis de algunos cuadros del pintor flamenco Pieter Brueghel, "el Viejo."

En el caso de los poemas de Williams, el hecho de que aparezcan en una colección llamada Pictures from Brueghel y compartan el título con cuadros del pintor nos obliga a buscar las relaciones que puedan existir entre ellos. "La recolección" y "La siega" (figuras 1 y 2) pertenecen a la serie de pinturas que Brueghel dedicó a los meses del 
año. Aproximémonos a ellos con la lectura de los poemas y comencemos con "The Corn Harvest" (Williams 1962,9):

Summer! the painting is organized about a young 3 reaper enjoying his noonday rest Completely 6

Relaxed from his morning labors Sprawled 9 in fact sleeping unbuttoned on his back 12

the women have brought him his lunch Perhaps 15 a spot of wine they gather gossiping under a tree 18

whose shade carelessly

he does not share the 21

$$
\begin{array}{r}
\text { resting } \\
\text { center of }
\end{array}
$$

their workaday world 24

"The Corn Harvest" es una descripción bastante obvia de "La siega" (figura 1), gene-

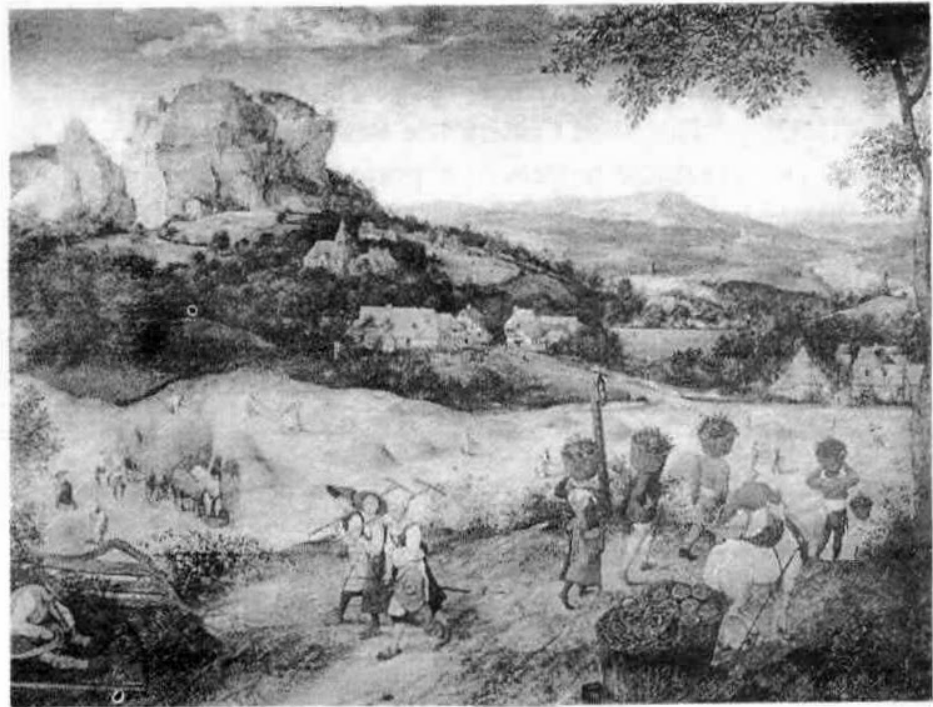
ral, si se quiere, pero obvia al fin: un joven segador descansa junto a un grupo de mujeres que come, mientras en el fondo se encuentran otras figuras que trabajan en dorados campos de trigo que se extienden hasta lo verde y lo gris del fondo. Williams sólo se refiere a lo que se encuentra en primer plano, a la derecha, de ahi que no podamos decir que la 
descripción que su poema hace del cuadro sea detallada: sus ocho estrofas de tres versos incluyen frases y enunciados, sin puntuación, cuyo número variará según el lugar en donde se supongan encabalgamientos (1. 3, 6, 12, 21). Cuando leemos un poema como éste lo hacemos como alguien que recorre un cuadro: ciertos elementos nos hacen fijąrnos en ciertas áreas, otros nos obligan a saltar a otro lado y buscar otras figuras, otros colores. En este hecho podemos encontrar una referencia a la forma en la cual el lenguaje visual funciona. Para darle sentido a las frases, tenemos que regresar a la estrofa anterior, avanzar y volver a retroceder para ver en dónde comienza y termina una idea. La línea 21 es la que hace más evidente esta característica y apunta a la diferencia entre leer un poema y leer un cuadro (normalmente y en nuestra tradición, de izquierda a derecha): el verso 21 nos obliga a considerarlo como parte de dos ideas diferentes: "They gather gossiping/ under a tree/ whose shade/ carelessly/ he does not share," o "He does not share the/ resting/center of/ their workaday world." Una misma frase, un mismo espacio, tiene que leerse dos veces para que lo que está junto a ella (antes y después) tome algún sentido. Entonces, resulta que el poema de Williams no sólo describe algunas de las figuras del cuadro de Brueghel, sino que presenta otra característica, tradicionalmente asignada a la representación visual y la incorpora a su representación verbal: la espacialidad.

Consideremos ahora el otro poema de Williams, "Haymaking" $(1962,8)$, para profundizar lo anterior.

The living quality of the man's mind stands out 3

and its covert assertions for art, art, art! painting 6

that the Renaissance tried to absorb but 9

it remained a wheat field over which the wind played 12

men with scythes tumbling the wheat in rows 15

the gleaners already busy it was his ownmagpies 18

the patient horses no one could take that from him 21 
Los detalles descritos en "Haymaking" son mucho menos que los de "The Corn Harvest": se nombra el campo de trigo, se menciona el viento que juega con él (lo cual es de por sí bastante irónico y más si consideramos que es el único sustantivo, el viento, al cual se le asigna un verbo conjugado en la descripción), algunos hombres que blanden guadañas, espigadores, urracas que apenas se ven, $y$, el colmo, la referencia a unos caballos, que por su calidad de pacientes suponemos son análogos al poeta. $\mathrm{Si}$ buscamos todos estos detalles en el cuadro tenemos que brincar de un lado a otro, ninguna lógica nos obliga a ver primero el viento (si es que se nos ocurre verlo) y al final los caballos -que además no están en un grupo común. Es más, si seguimos la lógica de primer plano y fondo que la perspectiva tradicional de representación pictórica occidental explota, no seguiremos ese orden. Si, además, leemos las frases iniciales que comentan sobre el pintor y sus aseveraciones furtivas acerca del arte renacentista y consideramos la última frase ("no one/could take that/from him"), que parece establecer que Williams sólo quiere referirse a lo que no podemos evitar quitarle al pintor, a lo fundamental; si hacemos esto seguramente pensaremos en alguien que ve un cuadro y trata de entenderlo. Williams parece intentar escapar de la descripción, enfatizar que no vale la pena perder el tiempo nombrando todo lo que ve porque al fin y al cabo nombrarlo no es presentar el cuadro. Pareciera que evita las características del lenguaje verbal (de ahí lo difícil que puede ser seguir el poema) y presenta sólo lo fundamental del cuadro sin violentarlo: lo fundamental en este caso es la espacialidad. La verdad es que esto no era nada nuevo cuando Williams trabajaba porque existía ya una tradición que consideraba al espacio como estrictamente ligado a la representación visual y lo enfrentaba a la temporalidad del arte verbal.

Recordemos, por ejemplo, a Lessing, quien en su libro Laocoönte (1776), aseveró que la literatura y las artes plásticas difieren en sus leyes fundamentales de creación ya que trabajan a través de diferentes medios. Las artes plásticas tienen como medio de simbolización el color y la forma en el espacio, mientras que la literatura hace uso de sonidos articulados en el tiempo. Las primeras expresan su tema gracias a la yuxtaposición de elementos, mientras que la segunda lo hace a través de elementos consecutivos. Para Lessing, ambas formas deben armonizar con la cualidad esencial de su medio, así que las artes visuales presentarán el aspecto visible de los objetos en yuxtaposiciones hechas en un instante de tiempo, mientras que la literatura debe basarse principalmente en alguna forma de secuencia narrativa.

Sin embargo, Joseph Frank (1945) expone que la literatura moderna sigue un camino que se opone a la concepción de Lessing, ya que se caracteriza por "espacializar" lo que esencialmente es temporal y ese parece ser el proyecto detrás de los poemas de Williams. La casi ausencia de verbos conjugados intenta dar la ilusión de que escapamos de la secuencia narrativa; los encabalgamientos, la peculiaridad de la línea 21 de "The Corn Harvest" (que también se repite en la línea 5 de "Haymaking"), la yuxtaposición de ideas, la forma misma de las estrofas impiden la lectura continua y fluida y nos hacen recorrer el espacio de la página de una forma diferente. Williams imita la estructura espacial de la pintura y describe una parte de lo que ésta representa; al hacerlo, como en muchos otros de sus poemas, también expresa el deseo 
de crear imágenes tan poderosas como las visuales, imágenes que no pierdan su espacialidad al ser puestas en movimiento por una voz (de ahí la casi ausencia de verbos conjugados). Por eso Williams pensaba: "Not ideas but in things" (Baym 1985, 1083) y suponía que un poema debía presentar el objeto al que se referia y que quien leyera debia, a partir del objeto, sacar sus propias conclusiones, generar sus propias ideas como si se enfrentara directamente al mundo. En otro poema llamado "Still Lifes," escribió "All poems can be represented by/still lifes not to say water-colors" (cit. por Dijkstra 1969, 197), y expresó el reconocimiento de su incapacidad de crear imágenes tan exactas como las de, digamos, una acuarela. Desde este punto de vista, los versos finales de "Haymaking" ("no one could take that from him") refuerzan el reconocimiento de las limitaciones del propio lenguaje, limitaciones que parecen quitarle lo esencial ( $y$ lo poderoso) al lenguaje visual (a pesar de buscar emular la espacialidad esencial de un cuadro).

Williams no parece realmente satisfecho con su resultado. Ahora bien, ¿por qué cree que el lenguaje visual es superior al verbal? ¿Por qué, como muchos otros, considera que una representación visual realmente re-presenta, vuelve a hacer presente algo más? Para contestar estas preguntas tenemos que recordar la tradición que, desde el siglo XV, ha privilegiado lo icónico y que ha supuesto que el sentido más literal de la palabra imagen es el de una imagen pictórica. Dicha tradición comienza, como apunta W.J.T. Mitchell (1986), con la suposición de que el sistema de perspectiva "artificial," desarrollado en el siglo $\mathrm{XV}$, no es en ningún sentido artificial y que en realidad se presenta a si mismo como una forma exacta de representar la forma en la que las cosas se ven, la forma en que vemos y, finalmente, la forma en la que las cosas son. La tradición se ve reforzada por explicaciones sobre cómo percibimos que se basan en modelos que suponen la formación de imágenes visuales; se asienta cuando, al suponer que nuestras ideas son en realidad imágenes de las cosas y las palabras, a su vez, son imágenes de tales ideas, se privilegia un "estilo directo" que se aparte de cualquier ornamento en el lenguaje verbal y que busque sencillez matemática en las palabras. Más adelante, estas suposiciones se modulan cuando, en el Romanticismo, la imagen gráfica pasa a un segundo plano y deja en su lugar a una imagen superior, interna, orgánica y pura; y llega a comienzos del siglo $\mathrm{XX}$ con el énfasis modemista en la imagen como una especie de estructura cristalina, un modelo dinámico corporizado gracias al poema. Recordemos a Williams: "Not ideas but in things."

Sin embargo, suponer que el sentido literal de la palabra imagen es el de una representación pictórica, es sólo una forma de comprender lo que una imagen es. Existe otro punto de vista que consideró que el sentido "literal" del término no era pictórico, que incluso era antipictórico. Mitchell lo describe así:

Se trata de la tradición que comienza, por supuesto, con el relato de la creación del hombre "a imagen y semejanza" de Dios. Las palabras que ahora traducimos como imagen (el hebreo tselem, el griego eikon y el latin imago) se comprenden correctamente cuando, como los comentaristas insisten, se les considera una "semejanza" espiritual, general y abstracta y no una figura material. La adición normal después de "imagen" de la frase "y semejanza"(demuth en hebreo, homoioos en 
griego, y similute en latín) no debe comprenderse como si se tratara de dar más información sino como intentando evitar una posible confusión: "imagen" debe comprenderse no como "figura," sino como "semejanza," como similitud espiritual. ${ }^{2}$ $(1986,31)$

Ahora bien, ¿cómo fue que a este concepto de semejanza espiritual se le asignó la palabra imagen, confundida con el concepto de representación pictórica? Según Mitchell, la confusión se debió a un "desplazamiento" metafórico, a la búsqueda de cierta analogía concreta que se volvió literal debido "a las presiones de tendencias idólatras entre pueblos cercanos y entre los mismos israelitas" (35). Un análisis de la forma en la cual se dio dicho desplazamiento resultaría fundamental para cualquiera que se dedique a estudiar las relaciones entre las palabras y las imágenes visuales. Lamentablemente el tema es muy superior al alcance de este ensayo. Por lo pronto, conformémonos con mencionar que la tradición que consideró la noción de imagen como semejanza espiritual permaneció debajo de la que igualó a la imagen con una representación pictórica y que, en la primera, quisiera insertar el poema de Heaney, "The Seed Cutters" (1975, xi).

They seem hundreds of years away. Breughel,

You'll know them if I can get them true.

They kneel under the hedge in a half-circle

Behind a windbreak wind is breaking through.

They are the seed cutters. The tuck and frill

Of leaf-sprout is on the seed potatoes

Buried under that straw. With time to kill

They are taking their time. Each sharp knife goes

Lazily halving each root that falls apart

In the palm of the hand: a milky gleam,

And, at the centre, a dark watermark.

$\mathrm{O}$ calendar customs! Under the broom

Yellowing over them, compose the frieze

With all of us there, our anonymities.

14

Las obras que con certeza se pueden atribuir a Brueghel son cerca de cuarenta y entre ellas, ninguna representa a unos sembradores de papa. ${ }^{3}$ Así que, aunque el poema parecería ser la descripción de cierta escena que, si consideremos la alusión a Brueghel en el primer verso, podría deberse al pintor, la verdad es que no es así. Heaney describe una escena que inventa a partir de los cuadros de Brueghel. Consideremos "La siega" (figura 2) y comparemos varios de sus elementos con los descritos en "The Seed Cutters." En la pintura, un grupo de mujeres que forman un círculo comen bajo la sombra de un árbol. En el poema, un grupo de personas arrodilladas, bajo un seto, forman un medio círculo y el viento atraviesa un cortavientos. En el cuadro, el cortavientos está al fondo a la derecha. La papa que germina, con todas sus partes, en el poema está enterrada; así que no podriamos verla en un cuadro pintado como Brueghel pintaba, sólo veriamos la paja bajo la cual se supone que está. "With time to kill/ They are tak- 
ing their time," parece ser un comentario bastante acertado sobre la figura que descansa bajo el árbol; la mujer que corta el pan en el cuadro es análoga a las figuras que, con cuchillos, parten los bulbos, de cuyo centro escurre el liquido de la papa. El poema entonces se refiere a ese centro y lo nombra "a dark watermark," una marca de agua como la del papel del cual están hechos los calendarios a los que en seguida se menciona. Pero, ¿son estos calendarios o sólo se tiene una referencia al hecho especifico de que Brueghel representaba en sus cuadros los diferentes meses a través de las actividades comunes a cada temporada del año? ¿Cambiaría nuestra lectura si consideramos que "The Seed Cutters" es parte de una colección y se localiza inmediatamente después de "Sunlight," poema en el que se detallan las labores domésticas de una casa rural, y que todo el libro (North) hace referencia a lo subterráneo, a lo que realizan "anónimos" como los campesinos de los cuadros de Brueghel, como la mujer que en "Sunlight" realiza sus tareas domésticas o, incluso, como nosotras, las lectoras de un poema?

Heaney parece burlarse de esa tradición que supone que una imagen visual es más poderosa que las imágenes que pueden producir las palabras y describe una escena con elementos análogos a los de "La siega." Maticemos un poco, porque en ese matiz podremos entender parte del proyecto de Heaney a lo largo de North: la escena de los sembradores de papa parece existir en cierta memoria común que incluiria las escenas rurales, los meses del año, las labores propias del campo, la casa donde transcurrió la infancia. Por extraño que pueda parecer, alumnos míos leen el poema de Heaney, ven reproducciones del cuadro de Brueghel y piensan en escenas del campo mexicano. Y es que como Simon Schama escribe, "once a certain idea of landscape, a myth, a vision, establishes itself in an actual place, it has a peculiar way of muddling categories, of making metaphors more real than their referents; of becoming, in fact, part of the scenery" (1996, 61).

Heaney, en "The Seed Cutters," crea "escenas" que todos entendemos y que surgen de vivencias, de representaciones que hayamos visto, de paisajes reales que "leemos" según lo que consideramos un paisaje debe ser, Según Wied, los cuadros de Brueghel presentan una "visión tan profundamente arraigada en nuestro 'musée imaginaire,' que terminamos por asociar la pintura de Brueghel a un paisaje [...] real" $(1995,25)$. Ese "museo imaginario," esa memoria común que pasa subterránea en los sembradores de papas, en los que cosechan el trigo, es un tremedal (utilizando una metáfora del mismo

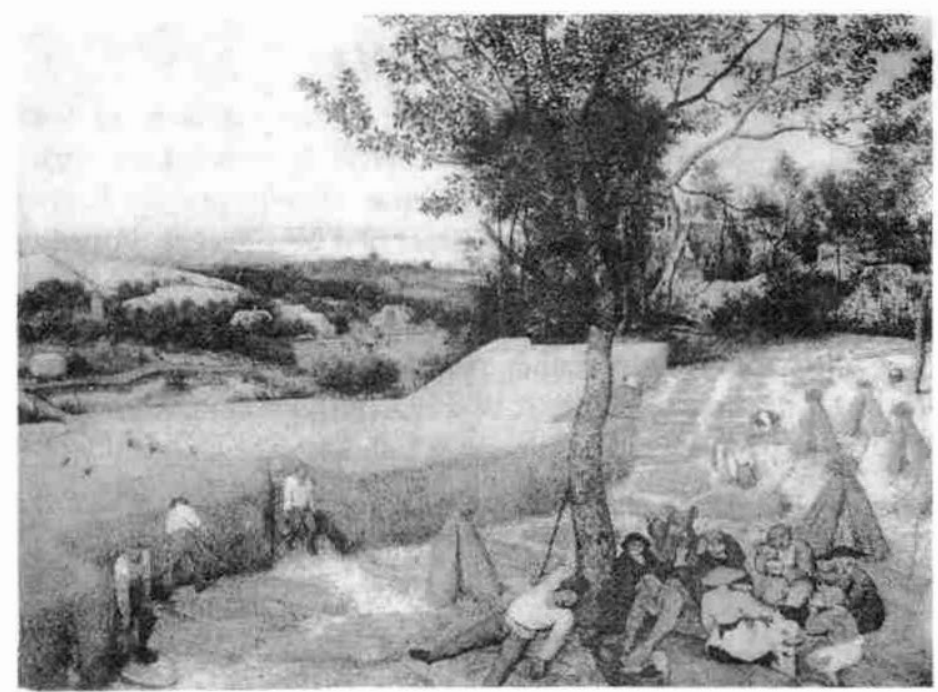


Heaney), un terreno pantanoso, abundante en turba y cubierto de césped, que retiembla cuando se anda sobre él. ¿Para qué sólo describir el campo de trigo pintado por Brueghel si sabes que debajo de lo que ves, en nuestro caso paja amarilla, hay elementos escondidos, "bancos de memoria" que retiemblan cuando andas sobre ellos y que componen el friso de "nuestros anonimatos"? ¿Para qué describir una escena real si la manera en la que la ves, lo que ves en ella, ha quedado determinado por lo que conoces, y entre eso que conoces bien puedes incluir un cuadro?

Valerie Robillard (1998) marca varias características que una ekphrasis debe tener respecto de la obra visual a la que se refiere y que, entre otras, incluyen alusiones al cuadro, analogías con el mismo, transposición de sus temas, normas y convenciones, recontextualización y autorreflexión. Todos estos elementos, como hemos visto, aparecen en el poema de Heaney y se relacionan con la idea de generar imágenes verbales que sean estructuras análogas, semejanzas que no necesariamente se relacionen con lo visual. En el fondo de esta concepción subyace la noción de que una representación visual funciona también por analogías y semejanzas y que no es tampoco la forma perfecta de re-presentar. Por lo pronto, recordemos que las ekphrasis funcionan de muchas formas y que son lugares clave en donde podemos encontrar nociones especificas sobre el lenguaje y la representación.

\section{Notas}

'Este trabajo se presentó en el ciclo Adaptación, interpretación, reescritura: los horizontes del texto literario, el 28 de marzo de 2001, en la Facultad de Filosofia y Letras, UNAM.

${ }^{2}$ La traducción de las citas de Mitchell es mía.

${ }^{3}$ Aqui habría que recordar que la papa es originaria de América. Resultaría apasionante trazar el camino que recorrió el tubérculo hasta afianzarse como cultivo esencial en la alimentación europea e investigar con exactitud cuándo ya se cultivaba comúnmente en el viejo continente. Tal vez Brueghel ni siquiera llegó a ver el campo de su país cubierto de sembradíos de papas.

\section{Obras citadas}

Baym, Nina, et al . 1985. The Norton Anthology of American Literature. 2a. ed. vol. 2. Nueva York \& Londres: W.W. Norton \& Company.

Dijkstra, Bram. 1969. Cubism, Stieglitz and the Early Poetry of William Carlos Williams. The Hieroglyphics of a New Speech. Princeton, New Jersey: Princeton University Press.

Frank, Joseph. 1945. "Spatial Form in Modern Literature." The Sewanee Review LIII (Spring, Summer, Autumn.)

Heffernan, James A.W. 1993. Museum of Words. The Poetics of Ekphrasis from Homer to Ashbery. Chicago \& Londres: The University of Chicago Press.

Mitchell, W.J.T. 1986. Iconology. Image, Text, Ideology. Chicago \& Londres: The University of Chicago Press. 
Robillard, Valerie. 1998. "In Pursuit of Ekphrasis (an intertextual approach)." Pictures into Words. Theoretical and Descriptive Approaches to Ekphrasis. Ed. Valerie Robillard \& Els Jongeneel. Amsterdam: VU University Press.

Schama, Simon. 1996. Landscape and Memory Nueva York: Vintage Books.

Wied, Alexander. 1995. Brueghel. Milán: Electa.

\section{Ilustraciones}

Figura 1. Brueghel, Pieter, La siega (1565). Óleo sobre tela, $118 \times 160.7 \mathrm{~cm}$. En Wied $(1995,103)$.

Figura 2. Brueghel, Pieter, La cosecha (1565). Óleo sobre tela, $117 \times 161 \mathrm{~cm}$. En Wied $(1995,102)$. 